\title{
Paul Ricoeur: a ética da solicitude questiona a educação
}

\section{Paul Ricoeur: the solicitude ethics challenges education}

\author{
Rosa Maria Filippozzi Martini*
}

*Centro Universitário La Salle Unilasalle, Canoas, RS, Brasil. filippozzi.rosa@gmail.com

\begin{abstract}
Resumo
Este ensaio busca apresentar a ética da solicitude de Paul Ricoeur como um questionamento para a educação. Ricoeur buscou em sua ética distinguir a moral da ética, priorizando essa, mas colocando a moral como núcleo dela. Para o autor, trata-se de visar à vida boa com o outro em instituições justas. O autor insere a questão ética no problema da identidade narrativa de si mesmo como um outro. Ricoeur caracteriza a ética como um aceitar o outro como um si mesmo, visto que, se posso me perceber como um outro, posso também aceitar o outro como a mim mesmo. Esse movimento implica na justiça, quando referido às instituições.

Palavras-chave: ética, moral, justiça, si mesmo, outro.
\end{abstract}

\section{Abstract}

This essay presents Paul Ricoeur's ethics of solicitude as a challenge to education. Ricoeur proposes a distinction of ethics from moral, but including moral as the core of ethics. To him, the aim is a good life with the other, in fair institutions. Ricoeur engages the question of ethics in the self-narrative as a other. Ricoeur states that if it could be possible to see myself as another, it could be also possible to see the other like my self. According to him, this process implies justice, if it is related to institutions.

Keywords: Ethics, moral, justice, selfness, otherness. 


\section{pro.posıções}

\section{1 - Introdução}

O presente artigo trata do significado da narrativa e suas implicações para uma ética da solicitude, como reconhecimento do outro como a si mesmo, em um mundo de instituições justas. Essa afirmação de Ricoeur torna-se um questionamento fundamental para a educação. Aprender a narrar e produzir narrativas de si, colocando o ser humano no centro de sua humanidade que é o domínio da fala e da escrita, poderá ser uma forma de reflexão ética, estética e moral, com ressonâncias fundamentais para a formação e a educação do ser humano. Ricoeur (1990) aproxima a ideia de tecer um enredo com a questão da ação, pois é por meio de variações imaginativas do exercício de narrar que se pode enfrentar a dialética entre ipseidade e mesmidade, utilizando os recursos da ficção literária para fazer frente à problemática da identidade pessoal, tão importante para a formação humana. Quando Dilthey (1986) abordou o conceito de totalidade da vida, de conexão vital, o que ele tinha em mente era a importância das histórias de vida, tanto para as ciências humanas como para a formação e a educação ${ }^{1}$.

Ricoeur (1990) nos fala a respeito das narrativas como uma concordância discordante que surge nas vicissitudes de uma história de vida. A concordância é o princípio de ordem, já mencionado por Aristóteles, na tragédia grega, como agenciamento de fatos. A discordância se refere às mudanças ocorridas na vida do personagem, às diversas mediações que uma história contada opera, tais como componentes paradoxais da ação, causas, acasos que formam a dialética, como síntese heterogênea de uma narrativa de vida e que confere uma potência de configuração que se caracteriza como poiesis em si mesma. Há, pois, na narrativa de uma história de vida, um princípio de identidade dinâmica que se constrói à medida que a história é narrada.

O que pensamos debater neste ensaio é a narrativa de si como forma de educar e estimular o educando para aprender a avaliar a si mesmo, refletir sobre seus interesses, seus projetos e suas ações cotidianas, no sentido de perceber a si mesmo como um ator capaz de assumir a responsabilidade por seus atos e por sua vida, na medida em que se espelha na sua própria narrativa. Por outro lado, a narrativa de uma história de vidasempre se situa numa

\footnotetext{
${ }^{1}$ Dilthey (1986), em sua Critica de la razón histórica, enfatiza a importância das narrativas a partir das vivências e dos seus três momentos: vivência, expressão e compreensão para a pesquisa histórica.
} 


\section{pro.posições}

comunidade e em seus valores, envolve histórias de interação com outros e apela para o reconhecimento do outro e da maneira como ele é acolhido pelo sujeito que se narra.

\section{2 - Imaginação e narratividade}

Segundo Azevedo e Castro (2002), Ricoeur explorou em Husserl a consciência temporal e imaginante. Para a autora, a inovação de Ricoeur (1983, 1984 ) no domínio fenomenológico da imaginação temporal, é sua articulação com o campo volitivo, ou seja, o campo da ação. Essa articulação nos permite compreender o homem como um ser de projetos. Há três estruturas que esclarecem o projeto: o decidir, o agir e o consentir. Quando alguém decide, compromete-se e oferece à reflexão o fluxo vital da própria consciência que se transcende, no sentido da realização de algo no mundo. Sendo o projeto algo irreal, a sua inscrição no real depende da moção voluntária, o pragma, o que está resolvido e em vias de atualizar-se, ou o já feito. A decisão exige ainda o consentimento. O consentir é a anuência do sujeito ao projeto realizado e implica em reflexão e na possibilidade do narrar. Esses três momentos são semelhantes aos das mimeses I, II, e III, pois, na mimese I, se pratica a urdidura de uma narrativa por um processo de configuração; na mimese II, os interlocutores recebem, concordam, discordam e interpretam a narrativa; e na mimese III autores e interlocutores se envolvem com um processo de reconfiguração da narrativa que pode abrir novas possibilidades para ela. Ora, narrar é dizer quem fez algo, por que e como, instalando no tempo a conexão desses pontos de vista. A narrativa permite uma articulação entre enredo e personagem e enseja a confrontação de uma pesquisa virtualmente infinita, no plano dos motivos, e um questionamento finito de atribuição a alguém. Embora se possa constatar, nesse processo, uma certa antinomia, a narrativa resolve à sua maneira esse problema, conferindo ao personagem uma iniciativa, isto é, o poder de começar uma série de fatos, sem que esse começo tenha que ser absoluto, mas apenas um começo no tempo que permite ao narrador o poder de determinar o começo, o meio e o fim da narração. À medida que se faz coincidir a iniciativa do personagem e o começo da ação, se constitui, em seus múltiplos aspectos, a réplica poética da identidade narrativa. Dessa correlação entre ação e personagem da narrativa se constitui a dialética de concordância e discordância, desenvolvida pelo enredo da ação. Na linha da concordância, a dialética consiste na singularidade de uma vida considerada ela mesma como uma totalidade temporal. Segundo a discordância, esta totalidade temporal está ameaçada pelo efeito de ruptura de eventos imprevisíveis, tais como encontros, 


\section{pro.posıções}

acasos etc. A síntese concordância - discordância faz com que a contingência dos fatos contribua para uma necessidade de alguma maneira retroativa da história de uma vida, implicada na identidade do personagem (Ricoeur, 1983, 1984).

\section{1 - Identidade narrativa}

Segundo Ricoeur $(1983,1984)$, a pessoa, compreendida como personagem de uma narrativa, não é uma identidade diferente de suas experiências, na medida em que essa pessoa partilha da identidade dinâmica da própria história que é narrada. A narrativa constrói a identidade do personagem, aprofunda sua experiência de si mesmo e do mundo. Podemos chamá-la de identidade narrativa, pois sua identidade se constrói à medida que sua própria história é narrada e tem como regra de desenvolvimento a dinâmica das três mimeses, ou seja, a configuração (mimese I), a interpretação (mimese II) e a reconfiguração (mimese III). Essa identidade da história completa a identidade do personagem. Ricoeur (1990) acentua que essa forma de dialética concordante-discordante precisa se inscrever na dialética da mesmidade e da ipseidade. Contamos, portanto, de um lado com a mesmidade de um caráter e, de outro, com a necessidade de manter-se como um si mesmo. Podemos constatar que Ricoeur usa o conceito de mesmidade, como o aspecto de autoidentificação, e o termo ipseidade, como o movimento de reflexão, de percepção do si mesmo. Essa percepção do si mesmo não é egocentrada e implica na interação com o outro para que se dê a esse autor o reconhecimento. Não é só de si mesmo, de sua mesmidade e ipseidade, que esse sujeito da narrativa fala, ele não se refere a ele como um eu solitário, mas de um si mesmo que se reconhece nos outros que interagem com ele e da comunidade à qual pertence, como alguém que constrói sua confiança no mundo, no outro e em si, podendo estender esse si mesmo a qualquer problemática mais universal que este si mesmo possa perceber, desde problemas mais próximos, como os de sua família e comunidade, até os mais gerais, como o problema ecológico, a violência e a fome no mundo. Assim, a função mediadora que a identidade narrativa exerce entre a mesmidade e a ipseidade se confirma pelas variações imaginativas, às quais a narrativa submete essa identidade. Essas variações não são somente aceitas, mas a própria narrativa as cria e as investiga. Ricoeur (1983) frisa a importância da literatura, que consiste em um vasto laboratório, para que possamos constatar essa dialética de tornar manifestas as fontes de variação da identidade narrativa. Segundo Garrido (1994), para o 


\section{pro.posıções}

encontro com a própria identidade, faz-se necessário o esclarecimento da dialética entre identidade como idem (mesmidade no tempo) e identidade como ipse (reconhecimento de si mesmo nas variações temporais e nas relações com os outros). Essa afirmação de Garrido com relação à educação sugere que uma educação que enfatize a identidade como mesmidade seria, na visão de Freire (1976a), uma educação bancária. A educação que considera as identidades idem e ipse numa dialética temporal seria uma educação libertadora, que se propõe a considerar cada criança, cada educando como um ser único e especial que irá narrar sua identidade segundo um processo crítico e formador.

Maas $(2000)^{2}$, em um estudo sobre o romance de formação, Bildungsroman, aponta para o estabelecimento do gênero romance como um exemplo significativo, visando ao processo de aperfeiçoamento histórico e político do indivíduo burguês, na Alemanha dos últimos 30 anos do século XVIII. O mais clássico dessa forma de romance foi o de Goethe, intitulado Os anos de aprendizado de Wilhelm Meister (1796).

No Brasil, essa apropriação do romance de formação ocorre, tardiamente, aparecendo, pela primeira vez, com a obra de Joaquim Nabuco (1900), intitulada Minha formação. Nabuco era um aristocrata do início do século XX, 1900, que combatia a escravidão. Seu romance foi de formação, no sentido em que ele relata seu desenvolvimento como ser humano e a forma como foi percebendo o mundo. Nesse livro, defende a generosidade dos escravos, os quais admirava pela sua doçura, percebida nas amas, e pela coragem e resistência observadas nos homens que trabalhavam nos engenhos. A partir dessas experiências, empenhou-se totalmente na campanha abolicionista e caracterizava o Brasil como um paradoxo entre escravidão e desejo de democracia.

Maas (2000) menciona também a obra de Jorge Amado, Jubiabá (1935), e Os tambores de São Luís, de Josué Montello (1975). Nesses romances, segundo a autora, se constata a crise entre um caminho individual de formação burguesa e a relação com uma espécie de epopeia que pretende referir-se ao mundo social e aos movimentos de emancipação de um proletariado que se formava por meio da incipiente industrialização do país. O romance de formação de Josué Montello (1975), Os tambores de São Luís, contrapõe a liberdade do marginal à submissão das classes proletárias que temem o desemprego, tornando-se submissas ao poder dos empresários, em outro processo de industrialização, sob a ditadura militar que abre a

\footnotetext{
${ }^{2}$ Maas 2000 dá uma importante contribuição sobre o Bildungsroman na História da Literatura Brasileira, confirmando o que Ricoeur (1984) acentua em seu texto sobre o significado formativo da narrativa.
} 


\section{pro.posıções}

economia para o capital estrangeiro. Podemos constatar que o que há de comum nos romances de formação é a trama que enfatiza um desenvolvimento psicológico do protagonista do romance com um panorama de desenvolvimento de uma luta social peculiar a cada momento histórico. Essa contradição foi apontada por Lukcács(1989) sua como a contradição existente entre a infraestrutura e a superestrutura, e a forma como a luta de classes se insere nelas.

Josso $(1991)^{3}$ desenvolveu uma pesquisa, em sua tese de doutoramento, que entrecruzou a narrativa autobiográfica própria com outras narrativas, das quais retirou instigantes achados. Josso caracterizou seu método como pesquisa biográfica de formação. A pesquisadora buscou entrecortar e articular sua própria biografia com um grupo de cinco sujeitos, evidenciando as tensões dialéticas entre o individual e o coletivo, constatando como as narrativas de si podem se articular e evidenciar achados significativos ao longo do processo. O projeto de desenvolvimento da pesquisa de formação alcança sua amplitude não só porque define um interesse de conhecimento, mas também porque oportuniza o trabalho de sujeitos que buscam a consciência de si, de seu ambiente, como também a qualidade de sua presença no mundo. A pesquisa de Josso utilizou tanto a narratividade como a identidade narrativa para propor uma investigação participante com vistas ao desenvolvimento ético e político, tanto dos participantes como da pesquisadora, à medida que, na articulação das biografias. foram surgindo experiências comuns, com significados para o pesquisador e para os sujeitos da pesquisa.

Nolin (2007), em seu trabalho de doutorado, se refere ao romance de formação (Bildung) na França, que usa uma narrativa romanesca para apresentar o homem comum ou o burguês com seus problemas de não adaptação a um mundo que se desenvolve continuamente. Cita, entre outros, Emilio, on da Educação, de Rousseau (1973) e Zola (18401902). Para a autora, o romance de formação francês tem uma característica mais realista e de crítica social, como J'accuse, de Zola, que critica o antissemitismo na França, diferente do romance de formação alemão, mais idealista. Nolin (2007) acentua a importância para sua pesquisa desse tipo de romance, visto que o objetivo de sua pesquisa foi a arte como processo formador.

\footnotetext{
${ }^{3}$ Josso realizou uma interessante pesquisa sobre o significado formativo da narração, em que pesquisador e sujeitos da pesquisa empreendem um caminho formativo ao longo da pesquisa.
} 


\section{pro.posıções}

Ricoeur (1990), corroborando a pesquisa de Josso (1991) e de Nolin (2007), enfatiza que a teoria narrativa ocupa uma posição articuladora entre a teoria da ação e a ética. $\mathrm{O}$ autor se refere ao fato de que na teoria da ação começamos por uma descrição linear e lógica das ações. Ricoeur critica uma teoria da ação praticada pela filosofia analítica por ser abstrata e objetivante e seguir somente a lógica da ação. De qualquer forma, é preciso, em um outro momento, reunir as ações, seus agentes e suas interações, porque precisamos articular as ações em um todo significativo que atesta a unidade de configuração sob uma relação particular de sentido que exprime a noção de regra.

Ricoeur (1990) observa o significado da regra nas ações e nas interações pertinentes a qualquer ofício, jogo ou arte que foi ensinado e aprendido, no contexto de uma cultura e de uma tradição. Segundo Ricoeur (1990), essa mesma relação entre práxis e narrativa se repete em um grau mais elevado de organização, quando se configura uma visão de totalidade, o que implica, segundo MacIntyre (2009) ${ }^{4}$, na unidade narrativa de uma vida. Ricoeur, comentando MacIntyre, afirma que nas histórias de vida é preciso que exista uma certa mistura de fabulação e experiência viva. O caráter instável e fluido da vida real, quando tomado retrospectivamente, precisa da ficção para organizar de forma significativa uma história de vida. Dessa forma, as narrativas literárias e as histórias de vida não se excluem, mas se completam em sua forma.

Com suas análises, Ricoeur (1990) não exclui a necessidade de veracidade de uma história de vida, principalmente no contexto de uma pesquisa, mas o autor afirma a importância de uma espécie de forma ficcional que torne a narrativa mais fluente e organizada em sua totalidade ética e estética. A aprendizagem da narrativa de si implica na admiração, no encantamento com as narrativas do outro, daqueles com quem se interage, da sua comunidade, aprendendo sobre seus valores e dos que dela participam. Aprender a se narrar implica na curiosidade de buscar outras narrativas de outras pessoas, de outras culturas, de outros tempos. Implica também em reconhecer o sofrimento do outro. Tudo isso forma um todo significativo no qual ética e estética se completam na busca de uma essência biográfica eleita e aprofundada pela reflexão.

\footnotetext{
${ }^{4}$ MacIntyre (2009), em sua obra Depois da virtude, concorda com Ricoeur sobre a importância dos contextos históricos e sociais para entendermos a ética e a moral, não como aspectos opostos, mas, sim, complementares.
} 


\section{pro.p̣osıções}

\section{2 - Da narratividade para a compreensão ética}

Para Ricoeur (1990), a questão da narratividade e a da identidade narrativa são o ponto de articulação entre uma teoria da ação e uma ética, na medida em que a narrativa desenvolve um espaço imaginário no qual se realizam experiências de pensamento, em que o julgamento moral se exerce de modo hipotético.

A teoria ética de Ricoeur se nutre das influências aristotélicas e kantianas, sem estabelecer uma ortodoxia entre uma e outra, mas dá uma atenção especial para as duas. Ricoeur (1990) esclarece o que julga importante nas duas tradições e dá prioridade à ética sobre a moral, sem excluir, porém, a necessidade de a visão ética passar pelo crivo da moral, visto que a legitimidade da norma orienta nossa meditação em diversas situações aporéticas, nas quais se exerce a reflexão sobre a ipseidade. A hipótese de trabalho de Ricoeur coloca a moral como tendo efeito limitado, mas legítimo e indispensável, na medida em que a ética envolveria a moral, constituindo-se numa espécie de núcleo da vida ética.

As duas tradições, a aristotélica e a kantiana, exerceriam uma função simultânea de subordinação e complementaridade. Como consequência dessa posição de Ricoeur, a visão teleológica implica na atribuição do predicado bom a ação, e a visão deontológica implica na atribuição do predicado obrigatório a ação. Essas visões, por sua vez, correspondem, em termos da designação de si, àquilo que chamamos de autoestima, e à visada deontológica corresponde o autorrespeito . Ricoeur acrescenta que há dilemas, em torno do dever, que se apresentam de tal forma que nenhuma norma certa pode oferecer um guia para o exercício, aqui e agora, do respeito, de modo que a autoestima aparece não só como a fonte, mas como o recurso ao respeito.

Consequentemente, a autoestima e o autorrespeito representam o estágio mais avançado do desenvolvimento de si mesmo ou de ipseidade. Ricoeur tenta responder dessa forma o célebre dilema de Hume, com relação ao hiato existente entre ser e dever ser, ou seja, entre descrever e prescrever. Segundo Ricoeur, à medida que se consegue demonstrar que o ponto de vista deontológico está subordinado a uma perspectiva teleológica, sem perder seu significado próprio, a separação entre ser e dever ser parecerá menos intransponível. Esse tipo de colocação de Ricoeur tem sido tratada em psicologia do desenvolvimento moral por Piaget (1977) em seu livro O juizo moral da criança, no qual descreve estágios do desenvolvimento 


\section{pro.posıções}

moral, como passagem da heteronomia para a autonomia, ou seja, para o processo de tomada de consciência da norma.

Por sua vez, Kholberg (1981), em seu célebre artigo "From is to ought: how to commit the naturalistic fallacy and get away with it in the study of moral development" e em uma pesquisa de toda uma vida, dedicada ao desenvolvimento moral, trabalhou com pesquisa qualitativa, recolhendo cerca de mil respostas a dilemas ético-morais. Habermas (1989), em seu livro Consciência moral e agir comunicativo, retoma e reconstrói as duas posições de Piaget e Kholberg, recolocando que, para além das considerações naturalistas da Psicologia do Desenvolvimento, o essencial é responder à questão: o que significa adotar um ponto de vista moral? Por esta posição, baseada mais em princípios deontológicos, Habermas foi acusado por Tugendhat (1996) de desenvolver uma certa forma de "terror prático". Portanto, as questões da ética e da moral vêm sendo debatidas com o peso da balança tendendo ora para o bem, ora para o dever, sempre buscando relações significativas entre ambos ${ }^{5}$.

Ricoeur (1996) tenta recolocar o problema, buscando uma solução que contemple os dois lados da questão. Ele considera a intencionalidade ética como a visão de uma vida boa com e para o outro em instituições justas (p. 257). Nessa colocação, Ricoeur engloba o querer o bem do outro, o bem para si mesmo, o bem para a comunidade local e para a comunidade global, nisto estando incluídas as questões da paz mundial, o cuidado com o meio ambiente e uma distribuição justa das conquistas da humanidade.

Enfim, Ricoeur afirma que toda a ética pressupõe um uso não saturado do predicado bom, ou seja, tudo o que faz uma vida boa e digna de ser vivida deve ser prerrogativa de todo e qualquer ser humano. O uso não saturado do predicado bom resulta que os conceitos "estima de si" e "respeito por si mesmo" soam abstratos e vazios, enquanto não houver o reconhecimento do outro, como outro. Nesse sentido, Ricoeur argumenta que aquilo que Aristóteles chamou de "vida boa" e que estendemos nas narrativas para planos de vida e unidade narrativa de uma vida só adquire sentido, se pudermos entrever nesses planos uma dimensão de realização do bem para todo e qualquer ser humano. Significa vida desde a raiz biológica dessa vida, o que implica na preservação do ambiente dessa mesma vida e no desenvolvimento pessoal, social, cultural e político dessa própria vida. Essa vida, desde sua

\footnotetext{
${ }^{5}$ Piaget (1977), em O juízo moral da criança; Kohlberg, em From is to ought: how to commit the nauralistic fallacy and get away with it in the study of moral development (1981) e Habermas, em Consciencia moral e agir comunicativo (1989) e, em The inclusion of the other (1998), concordam com Ricoeur que o significado ético e moral se refere fundamentalmente ao reconhecimento do outro como a si mesmo.
} 


\section{pro.posições}

raiz e em seu desenvolvimento, não é algo homogêneo e abstrato, mas, sim, alguém, uma pessoa humana com suas peculiaridades vitais, pessoais, históricas e culturais, mas justamente porque humana merece uma vida boa, no sentido de esse predicado bom seja atribuído por cada um na vida que lhe foi dado viver. Na verdade, isso que consideramos bom é tão frágil quanto a ação humana, e o que nos resta é aprender a interpretar a nossa própria vida em relação com o outro e com o mundo, em sua vulnerabilidade.

Essa forma de conceber a educação pode causar estranheza aos defensores do conteudismo e àqueles que acreditam que não cabe à Escola a formação ético-moral do educando, devido à diversidade cultural da qual o educando provém. Entretanto, aprender a se narrar e apreciar a narrativa do outro pode constituir-se em um potente recurso para o uso da língua e a aprendizagem de conteúdos históricos e literários.

\section{3 - A ética da solicitude}

Ricoeur (1990) recorre a Aristóteles na Ética a Nicômaco para aprofundar o que ele referia como visar à vida boa que se reflete como estima de si, sendo, portanto uma virtude referente a si mesmo, logo, aparentemente, solitária. A justiça endereçada à comunidade de caráter essencialmente político, mas como justiça em si mesma, aparece como núcleo de uma moral. Assim, se algo é considerado como uma finalidade boa, portanto como um bem, precisa ser estendido a todos. Além de Ricoeur destacar que a amizade, em Aristóteles, é um exercício de busca do bem, como uma espécie de egoísmo refinado (philantia), ele reivindica, justamente nesse ponto, a questão da falta, pois, como afirma o estagirita, um homem feliz precisa de amigos. Essa falta insere um elemento novo que é a alteridade, colocando a aporia segundo a qual: seria necessário amar-se a si mesmo para amar o outro? Aristóteles (1991) aponta nesse problema uma certa equivocidade, pois há diversos tipos de amizade: aquelas que se formam pela busca do bem, aquelas que buscam o útil e as que buscam o prazer. Assim a philautia, como amor de si mesmo, não será a realização direta da estima de si, mas será sempre mediatizada por um desejo de busca do bem para os amigos. Pode-se, portanto, observar que o desejo de busca do bem entre amigos envolve a mutualidade e a reciprocidade. $\mathrm{Na}$ amizade, a reflexividade do si mesmo não é abolida, mas redobrada, visto que orienta tanto a ação como os agentes para a busca do bem. Assim, se a amizade não é somente prazerosa ou útil, 


\section{pro.posições}

segundo Aristóteles, o que cada um compartilha é o melhor de si mesmo, ou seja, a parte pensante, o intelecto.

Segundo Ricoeur (1990), Aristóteles reconhece o significado da alteridade, na medida em que são o outro e o reconhecimento do outro que têm a possibilidade de buscar o bem que não sou capaz de buscar apenas por mim mesmo, exigindo iguais condições intelectuais para a busca e o reconhecimento do bem ${ }^{6}$. Esse reconhecimento leva o ser humano a valorizar a amizade mais do que qualquer outro bem exterior. Além disso, a amizade é uma atividade que envolve a busca do bem por ambos os amigos, envolvendo a ideia de mutualidade, reciprocidade e o reconhecimento de cada um, em sua forma própria de existir. Essa mutualidade e igualdade colocam a amizade no caminho da justiça, pois o compartilhar a amizade envolve poucas pessoas e, no caso da justiça, esses poucos dão lugar à distribuição do bem na escala de uma pluralidade, de uma comunidade política e histórica. Ricoeur avalia, então, que essa igualdade no plano intelectual que Aristóteles defende a partir da mutualidade se coloca como incerta, dada a fragilidade do ser humano e de sua própria vida sempre limitada.

Há, segundo Ricoeur (1982a), uma desproporcionalidade entre a aspiração ao bem, inteligível e abstrato da inteligência do ser humano, e o concreto de sua existência, de extrema labilidade e vulnerabilidade que, mesmo querendo o bem, é capaz de introduzir o mal no mundo ${ }^{7}$.

Ricoeur (1982a), ao refletir sobre a precariedade da existência humana e a fragilidade na busca do bem, descreve uma outra alternativa que não a simetria racional com relação ao bem, proposta por Aristóteles. É o que ele chama de "partilha", do dar e receber, o que não implica sempre em simetria, visto que as possibilidades de dar e receber nem sempre são iguais, em termos de possibilidade de iniciativa. Ricoeur propõe como elemento essencial dessa dissimetria a solicitude e, ainda, afirma que permanece no campo da ética e que aqui se trata da bondade em relação ao outro e não da obrigatoriedade da norma. Trata-se da simpatia de um ser humano que age e sofre e cuja iniciativa pode ser a compaixão ou a partilha da alegria e da dor. Essa simpatia não se confunde com piedade ou com qualquer outro

\footnotetext{
${ }^{6}$ Aristóteles, em Ética a Nicômaco, nos livros VII e VIII, fala sobre a importância da amizade e da justiça como reconhecimento do outro e reciprocidade, servindo sua obra de base para o trabalho de Ricoeur.

${ }^{7}$ Ricoeur(1982b), em "La simbolica del mal", fala da habilidade humana capaz de introduzir o mal no mundo. Ricoeur fala do simbolismo da mancha, do pecado, do livre arbítrio e da culpabilidade que são indícios da existência do mal no mundo.
} 


\section{pro.posıções}

sentimento - o que se pode compartilhar é nossa fragilidade, nossa contingência, reconhecida por cada um.

Conforme Ricoeur (1990), é possível quebrar a instância da obrigação e reencontrar um sentido ético que não é algo que se distancia da norma, mas que a torna muda diante de casos de consciência problemáticos. Ricoeur acentua o estatuto da solicitude como mais fundamental que a obediência ao dever. Esse é o estatuto espontâneo da benevolência, intimamente ligado ao fato de que receber é o mesmo que dar, como responsabilidade decorrente do reconhecimento do outro pelo si mesmo e do outro como a si mesmo, tendo em vista que a superioridade da autoridade que implica em agir segundo a justiça, na maioria das situações se apresenta de forma abstrata. Essa igualdade não é propriamente a da amizade, em que dar e receber se equivalem.

Ricoeur (1990) enfatiza nossa condição comum de seres vulneráveis, agentes e sofredores. O sofrimento, segundo o autor, não se reduz à dor física ou psíquica, mas à diminuição que o outro observa de sua capacidade de agir, de poder fazer, percebida como algo que atinge a integridade do si mesmo. Aqui, a iniciativa, em termos do poder fazer, parece voltar exclusivamente ao si mesmo, que dá sua simpatia, sua compaixão no sentido forte de desejar partilhar a alegria ou o sofrimento do outro. Na simpatia verdadeira, o si, cuja potência de agir é maior que a do seu outro, é afetado por tudo com relação ao outro que sofre e lhe oferece de volta a sua própria fraqueza.

Uma prova de extrema solicitude, na qual a desigualdade do poder pode ser compensada, é a troca de alegria em estar com crianças e jovens, auxiliando seu desenvolvimento ou saciando sua fome, não só física, mas de cultura e realizações. É também a hora da agonia de um ser humano que se refugia no murmúrio partilhado das vozes ou nas mãos que se buscam em um frágil aperto. O moribundo nada tem a oferecer senão a si mesmo e seu sofrimento. Mesmo assim, nessa relação podemos aprender e captar o sentido que nos ensina nossa finitude. O mais essencial na ética da solicitude é o aprofundamento da experiência do si mesmo como um outro, em sua relação espontânea que parte da constatação de que somos iguais em nossa vulnerabilidade e finitude. Assim o que importa não é a troca, nem a simetria, mas a experiência radical de nossa contingência.

Podemos concluir que o pensamento de Ricoeur (1990), com sua proposta de uma ética da solicitude, parte da fragilidade do bem e da condição finita e vulnerável que ronda toda a 


\section{pro.posições}

existência humana. É descobrindo essa fragilidade do estar jogado na existência, como afirma Heidegger $(2012)^{8}$, em Ser e tempo, que podemos descobrir que, em qualquer situação existencial, partilhamos com o outro nossa própria vulnerabilidade, da qual ninguém escapa, nem mesmo a própria natureza. Essa partilha significa que não posso estimar-me a mim mesmo sem estimar o outro como a mim mesmo. Segundo o autor, esse tu, e esse como a mim mesmo, atestam o lugar e o valor do outro como insubstituíveis em seus contextos sociais e naturais.

Ricoeur (1990) acentua, entretanto, que o viver bem não se limita às relações interpessoais, mas estende-se às instituições. A justiça apresenta características éticas que não estão presentes na solicitude. A justiça se entende pela instituição de uma estrutura do viver juntos, como uma comunidade histórica, povo, nação. A ideia de instituição se caracteriza por costumes comuns e não por regras restritivas. Esse seria o autêntico sentido do éthos do qual a ética extrai o seu nome. Ricoeur (1990) cita oportunamente Arendt (1981), na sua obra $A$ condição humana, que distingue e marca a distância que existe entre o poder em comum e a dominação9. A propósito dessa referência a Arendt, Ricoeur (1990) assevera que, por mais frágil que seja o poder, é a característica do agir e viver juntos que acrescenta ao sentido ético o ponto de indispensável aplicação de uma terceira dimensão que é a justiça. O autor adverte que sua concepção de justiça é diferente da deontológica e pragmatista de Rawls (1997), em sua Uma teoria da justiça ${ }^{10}$. Ricoeur refere-se à justiça como uma extensão do visar o bem, presente nas relações interpessoais, voltadas nessa instância para as instituições.

Ricoeur (1990) se refere ao conceito imemorial da ideia de justiça que aparece de forma mítica na tragédia grega e permanece nas sociedades secularizadas, não se esgotando nos sistemas jurídicos, exigidos, porém, por esses mesmos sistemas. $\mathrm{O}$ autor afirma que o sentido de injustiça é o que mais se manifesta, pois é ela que impera. Ricoeur ainda comenta que Aristóteles se refere ao mésotes tão característico da virtude aristotélica, menciona que é a igualdade proporcional que define a justiça distributiva. A igualdade aritmética não é

\footnotetext{
${ }^{8}$ Heidegger (2012), em Ser e tempo, procede a uma fenomenologia hermenêutica da existência em que descreve o homem como um ente jogado no mundo, como alguém que com o outro busca o sentido da relação entre ser e ente. Portanto a pergunta pelo sentido do ser que acontece na existência humana precisa do outro para ser formulada.

${ }^{9}$ Hanna Arendt (1981), em sua obra A condição humana, corrobora a obra de Ricoeur no sentido de que a condição humana acontece no momento que reconhecemos nosso destino comum e a necessidade que temos de agir em conjunto, reconhecendo o outro para evitarmos cair na barbárie e no totalitarismo.

10 John Rawls (1997), em Uma teoria da justiça, examina e afirma a prioridade da justiça sobre todas as virtudes, examinando seus princípios teóricos. Ricoeur não discorda totalmente de seus pontos de vista, mas qualifica seus estudos como muito abstratos.
} 


\section{pro.posições}

conveniente, porque a distribuição se baseia na natureza das pessoas e das coisas compartilhadas. A justiça distributiva se caracteriza em igualar duas relações, entre uma pessoa e um mérito. A justiça se baseia, portanto, em uma relação de proporcionalidade.

Para Ricoeur (1996) Aristóteles, assim como Rawls, tenta justificar uma certa ideia de igualdade, que não chega a ser igualitarismo. Qualquer que seja o matiz atribuído à igualdade, ela se apresenta na vida das instituições, como aspiração à justiça, da mesma forma com que a solicitude se apresenta nas relações interpessoais.

Ricoeur (1996) ainda relaciona a ética da solicitude, implicada na estima de si, com a moral relativa ao respeito de si. Como teólogo, cita o mandamento principal: ama teu próximo como a ti mesmo como cerne da moral. O autor insiste novamente que o homem, ser livre, mas limitado por sua contingência e labilidade, é capaz de aceder ao bem, mas também introduzir o mal no mundo. O mal ocorre em relação ao outro e ao mundo, e vai desde o descuido com o ambiente, à tentativa de influenciar o outro, quer por elogios ou ameaças; implica também em humilhação, em tortura e assassínio. Assim, a posição de Ricoeur com relação ao respeito pelo outro que implica no respeito por si mesmo coincide com a principal formulação do imperativo categórico de Kant (1986), que é considerar o ser bumano como um fim em si mesmo, ou seja, uma pessoa, insubstituível e merecedora de respeito. Entretanto, o autor frisa que o imperativo moral, para não se apresentar como uma abstração, precisa estar envolvido pela ética da solicitude.

A ética da solicitude pode parecer estranha para as teorias da educação, baseadas geralmente no cientificismo das teorias psicológicas do desenvolvimento e da aprendizagem e na ênfase metodologista e estratégica das metodologias do ensino. Essa posição científica com relação à educação lembra a ciência aristotélica e cartesiana que pretende fazer do educando alguém esclarecido e capaz de enfrentar o mercado de trabalho, que demonstre ter adquirido competências essenciais para evoluir no sistema educacional de qualquer país. Entretanto, essa forma de educar que esquece a solicitude esquece também que cada criança é um ser único e que o professor que exerce a solicitude é aquele que vê em cada aluno um destino original. 


\section{pro.posições}

\section{4 - O que podemos aprender com a ética da solicitude}

Concluímos com esta questão: o que podemos aprender...? Porque tanto Heidegger (1964) como Freire (1976b) afirmaram que ensinar é deixar aprender. Deixar aprender não significa abdicar do papel de professor, mas aprender que nunca estamos prontos para aprender a pensar, e aprender a deixar pensar é tudo o que um professor deveria procurar. Se ainda não aprendemos suficientemente a pensar, precisamos entrar com o outro, com solicitude, no caminho que nos leva a pensar ${ }^{11}$.

A ética da solicitude se manifesta no ofício de professor, como o que ainda não aprendemos a pensar. Essa aprendizagem do pensar tem que ser empreendida com o outro, em um caminho que sempre precisa ser recomeçado, dada a nossa precariedade e nossa finitude. Assim continuamente, com todos os recursos do mundo contemporâneo, que interligou todos os homens com as tecnologias digitais, precisamos atualizar nossa virtual potência de aprender. Precisamos aprender a pensar de diversas maneiras e em diversos ambientes, neles incluindo especialmente o ambiente digital. Precisamos aprender a reconhecer o desejo de saber, o desejo de criar e o desejo de narrar e reconhecer a narrativa do outro. Deixar aprender a pensar é reconhecer o outro como a si mesmo numa relação pedagógica que, sem abdicar da sua tarefa, reconhece esse fato como mais essencial: podemos aprender juntos a pensar.

Sugerimos que, em todos os níveis de ensino, na escola, na família e na comunidade, se desenvolva essa forma de autoconhecimento e de reconhecimento do outro como alguém no qual confiamos e com quem partilhamos histórias. Narrar e partilhar histórias é aprender sobre o mundo e os outros; é tentar afirmar sua história e de sua comunidade; é aspirar à afirmação de sua cidadania e daqueles que partilham seu próprio mundo; é estender muitos braços de solidariedade e dirigir-se para ações efetivas, decorrentes dos problemas identificados nas narrativas. Também na pesquisa em educação, trabalhar com histórias de vida significa envolver-se em um processo no qual pesquisador e sujeitos da pesquisa realizam uma formação mútua.

Numa época em que ocorrem tantas ameaças à identidade, seja pela forma de injustiças profundas da desigualdade de renda, como se pode verificar nas constatações de

\footnotetext{
${ }^{11}$ Tanto Heidegger (1964), em Qué significa pensar?, como Freire (1976b), em Educação como prática da liberdade, afirmam ao seu modo, em estilos diferentes, a ideia que só se aprende em um clima de liberdade e que ensinar é deixar aprender e aprender o mais profundo, ou seja, aprender a pensar.
} 


\section{pro.posições}

Pikety (2014), que afirma que, no século XXI, está ocorrendo a maior concentração de renda que já houve na história ${ }^{12}$, seja também pela violência nas cidades e nas guerras locais, pela falta de autenticidade e solidariedade nas relações interpessoais em função de uma sociedade extremamente competitiva, a probabilidade de uma identidade frágil é muito frequente. Seres humanos fragilizados por injustiças ou seres indiferentes, e que desejam cada vez mais, devido à sua labilidade e ambição, podem permitir que o mal se instaure no mundo. Devido a isso, a educação, além de habilidades e competências, deve fazer um contínuo convite a aprender a pensar, do qual ninguém pode ser excluído. Uma ética da solicitude age em prol do si mesmo como um outro e do cuidado com o ambiente.

Como conclusão, temos que tomar consciência de que o deixar pensar não se reduz a ele mesmo, mas implica em cidadania que trabalha com ações efetivas e participação na esfera pública, hoje facilitada pela internet. O deixar pensar é algo que exige o demorar-se nos problemas, é dar espaço para a reflexão, é dar tempo para que a maturidade se consuma. Se essa forma de solicitude puder ser incluída pelo professor como inerente à sua ética profissional, poderemos esperar gerações mais bem formadas, mas isso implica também na contínua formação do professor.

O professor que se educa de forma contínua e reflexiva para que no exercício de sua tarefa aprenda o verdadeiro sentido ético da solicitude será um professor que, para além de qualquer teoria ou estratégia, se concentre em reconhecer a originalidade e a diferença de qualquer aluno e, apesar dessa dificuldade, seja capaz de fazer o convite a esse ser único de palmilhar com ele os caminhos do pensamento. O professor que continuamente se educa é aquele que sabe que nunca está pronto para realizar sua tarefa.

\footnotetext{
${ }^{12}$ Piketty (2014) afirma, em sua obra Le capital au XXI siècle, que nunca houve uma tendência maior em concentração de renda em uma minoria, como no século XXI, com um prognóstico que tende a piorar, se os muito ricos não tomarem consciência de que esse fato poderá causar grandes catástrofes.
} 


\section{pro.posıções}

\section{Referências Bibliográficas}

Aristóteles. (1991). Ética a Nicômaco. São Paulo: Nova Cultural.

Arendt, H. (1981). A condição bumana. Rio de Janeiro: Forense Universitária; São Paulo: Ed. Universidade de São Paulo.

Azevedo e Castro, M. G. (2002). Imaginação em Paul Ricouer (Coleção Pensamento e Filosofia). Lisboa:Instituto Piaget.

Castro, M. G. A. (2002). Imaginação em Paul Ricoeur. Lisboa: Instituto Piaget.

Dilthey, W. (1986). Crítica de la razón histórica. Barcelona: Peninsula.

Freire P.(1976a). A pedagogia do oprimido Rio de Janeiro: Paz e Terra

Freire P.(1976b). A educação como prática da liberdade. Rio de Janeiro: Paz e Terra.

Garrido Vasquez, S. del C. (1994). A questão da educaşão e da identidade em Paul Ricoeur. Tese de Doutorado, Universidade Estadual de Campinas, Campinas. Retirado em 17 de junho de 2015, de www.bibliotecadigital.unicamp.br .

Habermas, J. (1989). Consciência moral e agir comunicativo. Rio de Janeiro: Tempo Brasileiro.

Habermas, J. (1998). The inclusion of the other. Cambridge. Massachusetts: The MIT Press.

Heidegger, M. (1964). Qué significa pensar? Buenos Aires: Editorial Nova.

Heidegger, M. (2012). Ser e tempo. Campinas, SP: Editora UNICAMP; Petrópolis, RJ: Vozes.

Josso, C. (1991). Cheminer vers soi Lausanne. Suisse: Éditions l'Age d'Homme.

Kant, I. (1986). Fundamentação da metafísica dos costumes. São Paulo: Edições 70.

Kohlberg, L. (1981). The philosophy of moral development (v. 1, pp. 97-101). New York: Harper and Row Publishers.

Lukács, G.(1989). História e consciência de Classe Rio de Janeiro: Elfos.

Maas, W.P. (2000). O cânone mínimo: o Bildungsroman na história da literatura. São Paulo: Editora da UNESP.

MacIntyre, A. (2001). Depois da virtude. São Paulo: EDUSC. 


\section{pro-posıções}

Nolin, D. (2007). L'acte créateur comme processus de formation existencielle du sujet apprenant artiste (191 pp.). Thèse du Doctorat en education, Université Du Quebec à Montreal.

Piaget, J. (1977). O juízo moral na criança. São Paulo: Mestre Jou.

Piketty, T. (2014). Le capital au XXIème siècle. Paris: Éditions Du Seuil.

Rawls, J. (1997). Uma teoria da justiça. São Paulo: Martins Fontes.

Ricoeur, P. (1982a). Finitudy culpabilidad. Madrid: Taurus.

Ricouer, P. (1982b). La simbolica del mal. In P. Ricouer, Finitudy culpabilidade (p.167). Madrid: Taurus.

Ricoeur P. (1983). Temps et récit. Tome I Éditions du Seuil, Paris.

Ricoeur P. (1984). Temps et récit Tome II Éditions du Seuil, Paris.

Ricoeur, P. (1990). Soi-même comme un autre. Paris: Éditions du Seuil.

Ricoeur P. (1996) Sí mismo como outro. Madrid:siglo veintiuno editores. (foram usadas as duas edições)

Rousseau, J.-J.(1973). Emilio, ou da educação. São Paulo: DIFEL.

Tugendhat, E. (1996). Lições sobre ética (5a ed. revista). Petrópolis RJ:Vozes,

Submetido à avaliação em 14 de fevereiro de 2015; aprovado para publicação em 28 de setembro de 2015 